\title{
Determining the Toll and Capacity of a Highway to Be Constructed in Parallel with Subway
}

\author{
Wen-Xiang $\mathrm{Wu}^{1}$ and Hua-Yan Shang ${ }^{2}$ \\ ${ }^{1}$ Beijing Key Lab of Urban Intelligent Traffic Control Technology, North China University of Technology, Beijing 1000144, China \\ ${ }^{2}$ Information College, Capital University of Economics and Business, Beijing 100070, China \\ Correspondence should be addressed to Wen-Xiang Wu; wwx816@gmail.com
}

Received 10 March 2014; Accepted 21 May 2014; Published 27 May 2014

Academic Editor: Chunlin Chen

Copyright (c) 2014 W.-X. Wu and H.-Y. Shang. This is an open access article distributed under the Creative Commons Attribution License, which permits unrestricted use, distribution, and reproduction in any medium, provided the original work is properly cited.

\begin{abstract}
This paper considers the problem of toll and capacity choice of a new highway with a bottleneck added onto an existing transit network under four ownership/tolling regimes: public fine toll, public flat toll, private fine toll, and private flat toll. Whenever fine toll and flat toll are imposed, in a competitive highway/transit network with constant returns to scale in road construction, an optimally designed and priced privately owned highway would produce positive net benefit justly equal to the total markup with respect to all autocommuters, whereas an optimally designed and priced publicly owned highway would lead to a deficit; that is, the toll revenues are insufficient to cover its all costs. The economic conditions to invest a new road are investigated under different ownership/tolling regimes.
\end{abstract}

\section{Introduction}

As a means to relieve congestion and improve transportation system efficiency, congestion pricing lends itself to two main purposes. First, congestion pricing seeks to remedy transport externalities by imposing a charge that reflects the monetized value of the externalities associated with driving. This leads to better utilization of transportation capacity as well as the need to build new roadway capacity. Second, congestion pricing has the potential to generate significant revenues; if widely adopted, it can become an important source of funding for transportation infrastructure. In developing or developed countries, government may suffer shortage of funds for public roads in the face of ever-growing congestion on urban and interurban traffic infrastructure. The toll revenues can be used to pay the maintenance, to pay existing debts, and to pay the investments in the extension of the network $[1,2]$.

In recent years, the joint optimization of toll and capacity, as decision variables in the problem, has been studied in order to produce significant benefits to the design and operation of both congestible urban and expandable road networks. One of the most famous findings (usually called self-financing theorem or Mohring and Harwitz rule) in transport economics proposed by Mohring and Harwitz is that under certain technical conditions the revenues from congestion pricing will be just sufficient for financing the costs associated with the optimal capacity supply [3]. The certain conditions state that (1) capacity can be adjustable in continuous increments, (2) capacity can be expandable at constant marginal cost, and (3) trip costs are homogeneous of degree zero in usage and capacity [4]. The Mohring and Harwitz rule was regarded as one of foundations of transportation economics [5]. In the context of Vickrey's bottleneck model of morning rush-hour autocongestion, a few researchers investigated the joint optimization of optimal toll and capacity under the circumstances where the first-best or second-best pricing applied and then examined whether it could be self-financing $[2,6]$. Arnott et al. stated that, whatever the tolling regime, the revenue collected from optimal toll on an isolated road is exactly sufficient to recover the costs of constructing optimal capacity if there are constant returns to scale in capacity provision [6]. More generally, the recovery ratio of the revenue to the costs with respect to optimal capacity equals the elasticity of capacity costs. This is 
because the generalized travel costs in the bottleneck model are homogeneous of degree zero in usage and capacity.

Nevertheless, there are still some aspects needed to launch an in-depth investigation. First, government may suffer shortage of funds for building more new roads to meet growing demand for travel. This has stimulated a rising interest in private supply of road capacity. Many private roads are in business around the world [7]. Recent research in transportation economics has focused on the road pricing and road network ownership that defines pricing and investment objectives (see [8-11]). A recent and probably the most complete analysis of private tolling on a parallel route network is given by [12], in which a variety of ownership regimes such as private and mixed duopolies are investigated. So, compared to a public traffic bottleneck, what if the traffic bottleneck is constructed and run by a private firm? Second, it is an important socioeconomic issue under what condition introducing a road into an existing transportation network is valuable in the sense of the total social welfare or net benefit [13]. Specifically, the efficiency of the whole network must be improved when introducing a new road by the government; namely, the total social welfare (social benefit minus total cost) is enhanced for the case with elastic demand. The net benefit (total revenue minus total cost) must be positive when introducing a new road by a private agency. It is worth investigating the relations between the entry conditions under various regimes and the parameters of the system. Third, the optimal road capacity provision has been mostly viewed as a standalone road network design problem conducted separately from congesting pricing (e.g. $[14,15])$. But for the strategic consideration of long-term optimal design of the capacity, the road designer should take into account both the level of capacity and prices in order to predict the volume of road users and toll revenues. If the bottleneck capacity is optimized separately from congestion pricing, how will it influence the investment choice and usage that determines the efficiency of the system? Finally, it seems desirable to highlight the impact of cost structure with respect to capacity on the Mohring and Harwitz result when the optimal tolling scheme is implemented and the capacity level is optimized. As a matter of fact, a few studies have paid attention to the impact of the cost structure on the Mohring and Harwitz result (e.g., [16-18]). If there are constant returns to scale in roads construction and strictly constant returns to road use, Newbery concluded that the optimal road user charge will recover all road costs [19]. Even if there are substantial economies of scale in providing pavement, Small et al. found that the road system as a whole comes close to self-financing because of the diseconomies of scope involved in the simultaneous production of road capacity for passenger cars and trucks [20]. More recently, assuming that transportation systems have, for a given capacity, the same total infrastructure cost but vary in the proportion of fixed costs and variable capacity cost, De Borger et al. found out that, compared to a benchmark infrastructure which has zero fixed costs, an infrastructure which has (ceteris paribus) a higher share of fixed costs leads to higher welfare for the regional government building it [21]. Moreover, even for capacity characterized by very high shares of fixed costs, financing of infrastructure is generally not an important issue as long as regions are allowed to toll through traffic.

In many large cities there exists a mass commuting mode and a highway with a bottleneck between home and workplace/central business district (CBD). This paper considers the toll and capacity choice for a new highway with a bottleneck added as alternative to the existing transit network. Similar to [13], the public authority (government) aims to seek welfare-maximizing, while the private firm aims to seek profit-maximizing. The time-varying toll is a completely flexible time-dependent toll for eliminating queue, and the flat toll is constant over rush hours. However, we here consider an existing transit network. Unlike the highway, the trains of a railway normally arrive on time no matter how crowded their carriages may be. Secondly, in reality, the rush-hour transit crowding is considerably serious. To a certain extent, crowding congestion will result in transit commuters' switch from departing on time to departing early or late for avoiding congestion. Accordingly, the travel costs of commuters on trains are not homogeneous degree of zero in link flow. In addition, in previous studies, the operating and maintenance costs (OMC) of a highway varying with the level of capacity and its usage are generally omitted or assumed constant and without loss of generality set to zero (see $[6,12]$ ). This leads to a substantial deviation from optimal solutions. In the paper, like $[2,19]$, taking into account the OMC, the joint optimization of toll and capacity, as decision variables concerning a highway with a bottleneck, is considered under various ownership/tolling regimes: public fine toll, public flat toll, private fine toll, and private flat toll.

The paper is organized as follows. Section 2 introduces the two basic models, respectively. The joint optimization of capacity and toll levels is studied under different ownership/tolling regimes. Section 4 investigates the conditions to invest the new highway project being investigated under various ownership regimes. And finally, Section 5 concludes the paper.

\section{The Basic Models}

Consider a simplified corridor network which contains two modes (railway and added-on highway) to provide transportation service between home or a resident area and a workplace or central business district. Mode " $a$ " represents an added-on highway with a single bottleneck which is located at the entering point of the highway and has a deterministic capacity of $s$ commuters per unit time. Mode " $b$ " represents an existing railway.

2.1. Train Mode. We first investigate the existing railway mode. Let $T_{b}$ be the on-train moving time. In general, all transit costs can be classified into two categories, that is, fixed costs and variable costs. Set the fixed costs to be zero for simplicity, since they are independent of the transit usage and do not affect the road toll decision. But, the variable costs generally increase with the number of passengers. Let $k_{b}$ denote the transit fare, which is mainly determined by the fixed costs and the operator's daily expenses on labor, 
fuel, electricity, and routine materials as well as the expected profit rate. It is assumed in this study that the transit fare should remain unchanged during a period of considerable length; that is, $k_{b}$ does not vary with the total demand. Let $r_{b}(t)$ be the departure rate of commuters on railway, $\left[t_{s}, t_{e}\right]$ the time window of train commuters' departure, and $r_{b}(t)=$ 0 when $t \notin\left[t_{s}, t_{e}\right]$. Let $m$ and $\xi$ be the number of trains dispatched and the length of time interval of dispatching trains during $\left[t_{s}, t_{e}\right]$, respectively, and $m \xi=t_{e}-t_{s}$. It is true that mass transit may bring people discomfort generated by body congestion at railway stations and in carriages if they are crowded. This body congestion also leads to the loss of independence and privacy by transit commuters [22]. In reality, rush-hour transit crowding is very serious. To a certain extent, crowding congestion will result in transit commuters' switch from departing on time to departing early or late to avoid congestion. Some studies introduced body congestion for modeling urban mass transit services $[23,24]$. Therefore, in this paper, we explicitly consider body congestion for modeling transit commuters' departure time choice. Like [25], for simplicity, we assume that the body congestion cost is proportional to the number of passengers in carriage and the transit time. Thus, the generalized cost per train commuter is given by

$$
c_{b}(t)= \begin{cases}\alpha T_{b}+k_{b}+\beta(\tilde{t}-t)+\psi \xi T_{b} r_{b}(t), & t \in\left[t_{s}, \tilde{t}\right], \\ \alpha T_{b}+k_{b}+\gamma(t-\tilde{t})+\psi \xi T_{b} r_{b}(t), & t \in\left[\tilde{t}, t_{e}\right],\end{cases}
$$

where $\psi$ is the body congestion parameter, $\psi \xi T_{b} r_{b}(t)$ is the body congestion cost, and $\tilde{t}$ is the departure time at which train commuters can arrive on time $t^{*}$; that is, $\tilde{t}+T_{b}=t^{*}$.

$\mathrm{Wu}$ and Huang stated that at equilibrium state $r_{b}\left(t_{s}\right)=$ 0 and $r_{b}\left(t_{e}\right)=0$. Consequently, in equilibrium, any train commuter is unable to find a departure time which can reduce his/her travel cost [25]. Letting $d c_{b}(t) / d t=0$, we get the departure rate from home by train:

$$
r_{b}(t)= \begin{cases}\frac{\beta\left(t-t_{s}\right)}{\psi \xi T_{b}}, & t \in\left[t_{s}, \tilde{t}\right] \\ \frac{\gamma\left(t_{e}-t\right)}{\psi \xi T_{b}}, & t \in\left[\widetilde{t}, t_{e}\right] .\end{cases}
$$

Thus, for any given $N_{b}$, the solutions to $t_{s}$ and $t_{e}$ are unique and given as

$$
\begin{aligned}
& t_{s}=\tilde{t}-\frac{\sqrt{2 \delta \psi \xi T_{b} N_{b}}}{\beta}, \\
& t_{e}=\tilde{t}+\frac{\sqrt{2 \delta \psi \xi T_{b} N_{b}}}{\gamma} .
\end{aligned}
$$

From (1)-(3), we easily get the generalized cost per train commuter

$$
c_{b}=\alpha T_{b}+k_{b}+\sqrt{2 \delta \psi \xi T_{b} N_{b}}
$$

2.2. Automode. We now consider that there is an added-on highway between an origin, such as a residential area, and a destination, such as a work place. When the highway is free from congestion (i.e., the arrival rate at bottleneck is less than the capacity), the free-flow commuting time is a constant $T_{a}$. If the arrival rate exceeds the capacity, a queue develops. Thus, the commuting time is given by

$$
T(t)=T_{a}+\frac{Q(t)}{s}
$$

where $t$ is the departure time from home, $Q(t)$ is the queue length (number of automobiles in front of the bottleneck), and $s$ is the bottleneck capacity.

Let $r_{a}(t)$ be the departure rate of autocommuters from home at time $t$; then the queue length is

$$
Q(t)=\int_{t_{0}}^{t} r_{a}(t) d t-s\left(t-t_{0}\right)
$$

where $t_{0}$ is the most recent time at which there is no queue.

Due to the finite bottleneck's capacity, some automobile commuters have to arrive earlier or later than the work starting time $t^{*}$, for preventing from having very high travel cost caused by queue. With such an assumption that the travel cost is proportional to the travel time and the schedule delay, we can formulate the generalized cost of an autocommuter as follows:

$$
c_{a}(t)= \begin{cases}\alpha T(t)+\beta\left(t^{*}-t-T(t)\right)+k_{a}, & t \in\left[t_{0}, \bar{t}\right] \\ \alpha T(t)+\gamma\left(t+T(t)-t^{*}\right)+k_{a}, & t \in\left[\bar{t}, t_{1}\right],\end{cases}
$$

where $k_{a}$ is the out-of-pocket cost (including parking fee, oil consumption, and highway fare), $\alpha$ is the unit cost of travel time, $\beta$ is the schedule penalty for a unit time of early arrival, $\gamma$ is that for a unit time of late arrival, $t_{1}$ is the time at which the queue ends, and $\bar{t}$ is the departure time at which an individual arrives at work at time $t^{*}$; that is, $\bar{t}+T(\bar{t})=t^{*}$. For rationality, the relation $\gamma>\alpha>\beta$ holds according to the estimates by [26].

Suppose that each autocommuter minimizes his/her generalized commuting cost through selecting the departure time. At a nontoll equilibrium state, any autocommuter is unable to find a departure time to reduce his/her own travel cost by unilaterally changing the departure time. In other words, $c_{a}(t)$ in (7) should be constant for all time $t \in\left[t_{0}, t_{1}\right]$. Letting $d c_{a}(t) / d t=0$, we have

$$
r_{a}(t)= \begin{cases}\frac{\alpha s}{\alpha-\beta}, & t \in\left[t_{0}, \bar{t}\right] \\ \frac{\alpha s}{\alpha+\gamma}, & t \in\left[\bar{t}, t_{1}\right] .\end{cases}
$$

Substituting (8) into (6), we get the queue length

$$
Q(t)= \begin{cases}\frac{\beta s\left(t-t_{0}\right)}{\alpha-\beta}, & t \in\left[t_{0}, \bar{t}\right], \\ \frac{\beta s\left(\bar{t}-t_{0}\right)}{\alpha-\beta}-\frac{\gamma s(t-\bar{t})}{\alpha+\gamma}, & t \in\left[\bar{t}, t_{1}\right] .\end{cases}
$$


Since $\bar{t}+T(\bar{t})=t^{*}, Q\left(t_{0}\right)=Q\left(t_{1}\right)=0$, and $\int_{t_{0}}^{t_{1}} r_{a}(t) d t=$ $N_{a}$, we can solve for the three time unknowns:

$$
\begin{gathered}
t_{0}=t^{*}-\frac{\delta N_{a}}{\beta s}-T_{a}, \quad t_{1}=t^{*}+\frac{\delta N_{a}}{\gamma s}-T_{a}, \\
\bar{t}=t^{*}-\frac{\delta N_{a}}{\alpha s}-T_{a},
\end{gathered}
$$

where $\delta \equiv \beta \gamma /(\beta+\gamma)$. As a result, the generalized commuting cost per autocommuter is

$$
c_{a}=\alpha T_{a}+k_{a}+\frac{\delta N_{a}}{s}
$$

The constancy of $c_{a}$ implies that, in equilibrium, no autocommuter can decrease his/her generalized commuting cost by changing his/her departure time. In other words, all individuals must experience identical travel cost, no matter when she or he leaves home. According to [6], the total travel cost of the autosystem, $c_{a} N_{a}$, is the sum of the total travel time $\operatorname{cost} \alpha T_{a} N_{a}+0.5 \delta\left(N_{a}\right)^{2} / s$, the total out-of-pocket cost $k_{a} N_{a}$, and the total schedule delay cost $0.5 \delta\left(N_{a}\right)^{2} / s$.

\section{Toll and Capacity Optimization}

Assume that, besides generalized costs, there is only one other price component of trip making for an autocommuter, namely, a toll $\tau$ (if levied). So, the perceived generalized price of the trip, $p$, can be written as the sum of the generalized cost $C$ and the toll $\tau: p=C_{a}+\tau$. Assume that the cost for the road construction will depend on its capacity $s$ only and that will be written as $G(s)$. It is to be interpreted as a per-unit-of-time cost, including capital and depreciation. Note that it is not the investment cost. For simplicity, we denote it by capital cost of capacity. According to $[2,18]$, we assume that OMC is the sum of a term which depends on usage (road damage due to usage), a term which is dependent on capacity, and a constant which is independent of both usage and capacity. The second term depends on natural degradation, due, for example, to bad weather conditions (induced potholes, cracks, and the like), and the third term represents other operating costs such as electricity expenditure. So, the OMC can be written as $M\left(N_{a}, s\right)=w(Q) N_{a}+v(Q) s+f$, where $Q$ is the quality of the road, $w(Q)>0$ the maintenance cost per usage, and $\nu(Q)>0$ the maintenance cost per capacity, the constant $f>0$ is independent of both usage and capacity. Here, we omit the quality dependency, and without loss of generality, the constant $f$ is set equal to zero since it has no effect on our decision making. Thus, $M(F, K)=w N_{a}+\nu s$, where the parameter $w$ can be interpreted as marginal demand (or usage) OMC, and the parameter $v$ is marginal capacity OMC. We indicate a downward convex inverse demand function by $D(n), d D(n) / d n<0$, and $d^{2} D(n) / d n^{2} \geq 0$, which also represents marginal benefits of commuters. So, its integral between 0 and $N$ gives aggregate benefits of trip making (per unit of time).

Due to the fact that a growing number of toll roads have been constructed and operated privately [27], we here concern two types of ownership: public ownership and private ownership. Principally, fine (time-varying) toll reflects real-time variation in congestion levels and achieves more efficiency. As a practical matter, however, deviation between ideal and actual implementation conditions occurs because of technological and public acceptance issues that make it difficult or costly to vary tolls over time at prescribed levels. Therefore, the flat toll is still widely adopted despite its deficiency. In this paper, we consider two types of polar tollsfine toll and flat toll. The combination of ownership and tolling produces four ownership/tolling regimes: public fine toll, public flat toll, private fine toll, and private flat toll.

3.1. Public Ownership. We first consider a publicly owned highway. A public authority would be to maximize social welfare surplus (social surplus): the difference between aggregate benefits of trip making and the aggregate social costs of making these trips possible. Thus, the social welfare maximization (SWM) problem is formulated as follows:

$$
\begin{aligned}
\max _{N_{a}, N_{b}, N, s, \tau} \operatorname{SW} & \left(N_{a}, N_{b}, N, s, \tau\right) \\
= & \int_{0}^{N} D(n) d n-N_{a} \cdot\left(\alpha T_{a}+K_{a}+\frac{\mu \delta N_{a}}{s}\right) \\
& -G(s)-w N_{a}-\nu s-N_{b} \\
& \cdot\left(\alpha T_{b}+K_{b}+\sqrt{2 \delta \psi \xi T_{b} N_{b}}\right) \\
\text { s.t. } \quad & \\
D(N) & =\alpha T_{a}+K_{a}+\frac{\delta N_{a}}{s}+\tau \\
& =\alpha T_{b}+K_{b}+\sqrt{2 \delta \psi \xi T_{b} N_{b}} \\
N_{a}+ & N_{b}=N,
\end{aligned}
$$

where $\mu=1$ for a flat toll and $\mu=0.5$ for a fine toll which can completely eliminate queuing (please see [6]).

From (13), we have

$$
\frac{\partial N_{b}}{\partial N}=\sqrt{\frac{2 N_{b}}{\delta \psi \xi T_{b}}} \cdot \frac{d D(N)}{d N} .
$$

From (14), we get

$$
\frac{\partial N_{a}}{\partial N}+\frac{\partial N_{b}}{\partial N}=1
$$

Together with (13)-(14), we obtain

$$
\frac{\partial N_{a}}{\partial N}=1-\sqrt{\frac{2 N_{b}}{\delta \psi \xi T_{b}}} \cdot \frac{d D(N)}{d N} .
$$


With (13), the objective function becomes

$$
\begin{aligned}
\max _{N, s} \operatorname{SW}(N, s)= & \int_{0}^{N} D(n) d n-N D(N) \\
& +(1-\mu) \cdot \frac{\delta\left(N_{a}\right)^{2}}{s} \\
& +N_{a}\left(D(N)-\alpha T_{a}-K_{a}-\frac{\delta N_{a}}{s}\right) \\
& -G(s)-w N_{a}-v s .
\end{aligned}
$$

The first-order condition of (18) with respect to flow $N$ leads to

$$
\begin{aligned}
\frac{\partial \mathrm{SW}(N, s)}{\partial N}= & -N_{b} \cdot \frac{d D(N)}{d N}-2 \frac{\mu \delta N_{a}}{s} \cdot \frac{\partial N_{a}}{\partial N} \\
& +\frac{\partial N_{a}}{\partial N} \cdot D(N)-\frac{\partial N_{a}}{\partial N} \cdot\left(\alpha T_{a}+K_{a}+w\right)=0 .
\end{aligned}
$$

With (13), (19) can be reduced to

$$
\tau=\frac{d D(N)}{d N} \frac{N_{b} \partial N}{\partial N_{a}}+\mu \frac{\delta N_{a}}{s}-(1-\mu) \frac{\delta N_{a}}{s}+w .
$$

Equation (20) shows that optimal road use requires imposition of the so-called Pigouvian toll, which is equal to the sum of marginal total travel cost with respect to all transit commuters $\left(N_{b}(d D(N) / d N) \cdot \partial N / \partial N_{a}\right)$, marginal travel cost with respect to autocommuters $\left(\mu \delta N_{a} / s\right)$, and marginal usage OMC $(w)$ minus the marginal fine toll $\left((1-\mu) \delta N_{a} / s\right.$ if existing).

The first-order condition of (18) with respect to $s$ yields

$$
\frac{\partial S W(N, s)}{\partial s}=\mu \frac{\delta\left(N_{a}\right)^{2}}{s^{2}}-\frac{d G(s)}{d s}-v=0
$$

Similarly, (21) can be reduced to

$$
\frac{\mu \delta\left(N_{a}\right)^{2}}{s^{2}}=\frac{d G(s)}{d s}+\nu .
$$

Equation (22) indicates that the capacity should be constructed to the point where the marginal benefits of capacity expansion (i.e., the value of aggregate travel time saving) is equal to the sum of the marginal capital cost of capacity and the marginal capacity OMC.

With (20) and (22), the total toll revenue $R$ is then

$$
\begin{aligned}
R= & \tau N_{a}+(1-\mu) \frac{\delta\left(N_{a}\right)^{2}}{s} \\
= & N_{a} N_{b} \cdot \frac{d D(N)}{d N} \cdot \frac{\partial N}{\partial N_{a}}+\frac{s d G(s)}{d s} \\
& +v s+w N_{a} .
\end{aligned}
$$

Thus, the net toll revenue $P R$ is

$$
\begin{aligned}
P R= & N_{a} N_{b} \cdot \frac{d D(N)}{d N} \cdot \frac{\partial N}{\partial N_{a}}+\frac{s d G(s)}{d s} \\
& +\nu s+w N_{a}-G(s)-w N_{a}-\nu s \\
= & N_{a} N_{b} \cdot \frac{d D(N)}{d N} \cdot \frac{\partial N}{\partial N_{a}}+\frac{s d G(s)}{d s}-G(s) .
\end{aligned}
$$

With constant return to scale in road construction, the elasticity of capital cost with respect to capacity $\rho$ is defined by

$$
\rho=\frac{d G(s)}{d s} \cdot \frac{s}{G(s)} \equiv 1 .
$$

Thus, we can rewrite (24) as follows:

$$
\begin{aligned}
P R & =N_{a} N_{b} \frac{d D(N)}{d N} \cdot \frac{\partial N}{\partial N_{a}}+(\rho-1) G(s) \\
& =\frac{N_{a} N_{b}(d D(N) / d N)}{1-\sqrt{2 N_{b} / \delta \psi \xi T_{b}} \cdot(d D(N) / d N)} .
\end{aligned}
$$

From (26), we have the following proposition.

Proposition 1. Whenever flat toll and fine toll are imposed, in a competitive highway/transit network with constant return to scale in road construction, an optimally designed and priced added-on highway for maximizing social welfare would lead to a deficit; that is, the toll revenues are insufficient to cover its all costs.

Proof. An optimally designed and priced added-on highway implies that both modes are all used; that is, $N_{a}>0$ and $N_{b}>$ 0 . Since $d D(N) / d N<0, P R<0$.

This is different from the Mohring and Harwitz rule. Mohring and Harwitz showed that, under certain conditions, an optimally designed and priced road would generate user toll revenues just sufficient to cover its all costs [3].

3.2. Private Ownership. When a private firm is in charge of the operating, maintenance, and construction of the road, the firm will seek the toll and capacity level to maximize its own net benefits (MNB). So, the MNB problem can be formulated as follows:

$$
\begin{aligned}
\max _{N_{a}, N_{b}, N, s, \tau} & P R\left(N_{a}, N_{b}, N, s, \tau\right) \\
& =N_{a} \tau+(1-\mu) \frac{\delta\left(N_{a}\right)^{2}}{s}-G(s)-w N_{a}-\nu s,
\end{aligned}
$$$$
\text { s.t. } \quad(13)-(14) \text {, }
$$

where $\mu=1$ for a flat toll and $\mu=0.5$ for a fine toll which can completely eliminate queuing. 
Similarly, with (13), we have

$$
\begin{aligned}
\max _{N, s} P R(N, s)= & N_{a}\left(D(N)-\alpha T_{a}-K_{a}-\frac{\delta N_{a}}{s}\right) \\
& +(1-\mu) \frac{\delta\left(N_{a}\right)^{2}}{s}-G(s)-w N_{a}-\nu s .
\end{aligned}
$$

The first-order condition of (18) with respect to flow $N$ is given by

$$
\begin{aligned}
\frac{\partial P R(N, s)}{\partial N}= & \frac{\partial N_{a}}{\partial N}\left(D(N)-\alpha T_{a}-K_{a}-\frac{\delta N_{a}}{s}\right) \\
& +N_{a}\left(\frac{\partial D(N)}{\partial N}-\frac{\delta}{s} \frac{\partial N_{a}}{\partial N}\right) \\
& +2(1-\mu) \frac{\delta N_{a}}{s} \frac{\partial N_{a}}{\partial N}-w \frac{\partial N_{a}}{\partial N}=0 .
\end{aligned}
$$

With (13), (29) can be reduced to

$$
\begin{aligned}
\tau= & -N_{a} \frac{d D(N)}{d N} \frac{\partial N}{\partial N_{a}}+\mu \frac{\delta N_{a}}{s} \\
& -(1-\mu) \frac{\delta N_{a}}{s}+w .
\end{aligned}
$$

Compared to the above welfare-maximizing toll in (20), the profit-maximizing toll excludes a marginal total travel cost with respect to all transit commuters but adds the markup with respect to each autocommuter.

The first-order condition of (18) with respect to flow $s$ is given by

$$
\frac{\mu \delta\left(N_{a}\right)^{2}}{s^{w}}=\frac{d G(s)}{d s}+\nu .
$$

Interestingly, while the toll rule is adapted to reflect the profit-maximizing objective, the capacity rule remains the same as the welfare-maximizing objective: the marginal benefits of capacity expansion equals the sum of the marginal capital cost of capacity and the marginal capacity OMC.

Thus, the net toll revenue $P R$ is

$$
\begin{aligned}
P R(N, s)= & -\left(N_{a}\right)^{2} \cdot \frac{\partial D(N)}{\partial N} \cdot \frac{\partial N}{\partial N_{a}} \\
& +\frac{s d G(s)}{d s}-G(s) \\
= & -\left(N_{a}\right)^{2} \cdot \frac{d D(N)}{d N} \cdot \frac{\partial N}{\partial N_{a}} \\
= & -\frac{\left(N_{a}\right)^{2}(d D(N) / d N)}{1-\sqrt{2 N_{b} / \delta \psi \xi T_{b}} \cdot(d D(N) / d N)} .
\end{aligned}
$$

From (26), we have the following proposition.

Proposition 2. Whenever flat toll and fine toll are imposed, in a competitive highway/transit network with constant return to scale in road construction, an optimally designed and priced added-on highway for maximizing net benefit would lead to a surplus, and the surplus is exactly equal to the total markup with respect to all autocommuters.

Proof. Similarly, as Proposition $1, N_{a}>0$ and $N_{b}>0$. With $d D(N) / d N<0$ and $(32), P R(N, s)>0$.

Of course, if a deficit result occurs, a private firm has no investment incentives when it is not subsidized by a government.

\section{Conditions to Invest the New Toll Road}

It is an important socioeconomic issue under what condition introducing the competitive project as an "add-on" road into an existing transportation network is valuable in the sense of the total social welfare [13]. Intuitively, the efficiency of the whole network (total social welfare) must be improved when introducing a new road by the government. Of course, the net benefit must be positive when introducing a new road by a private agency. In this section, we derive the condition to invest the new toll road under public ownership regime and private ownership regime, respectively. Without introducing a new road, in equilibrium, we have

$$
D(N)=\alpha T_{b}+K_{b}+\sqrt{2 \delta \psi \xi T_{b} N} .
$$

We denote $N_{o}^{*}$ as the solution to (32), and the social welfare maximization problem is formulated as

$$
\operatorname{SW}\left(N_{o}^{*}\right)=\int_{0}^{N_{o}^{*}} D(n) d n-N_{o}^{*} D\left(N_{o}^{*}\right) \text {. }
$$

After introducing a new road, we denote $N_{G}^{*}$ as the solution to the SWM problem. Clearly, $N_{a}+N_{b}=N^{*}$. Thus, we have the following lemma.

Lemma 3. In equilibrium, under public ownership, $N_{G}^{*}>$ $N_{o}^{*}>N_{b}$ if

$$
\begin{aligned}
\alpha T_{a} & +K_{a}+2 \sqrt{(k+\nu) \delta \mu} \\
& +\left.\frac{N d D(N) / d N}{1-\sqrt{2 N / \delta \psi \xi T_{b}} \cdot(d D(N) / d N)}\right|_{N=N_{o}^{*}}+w \\
& <\alpha T_{b}+K_{b}+\sqrt{2 \delta \psi \xi T_{b} N_{o}^{*}} .
\end{aligned}
$$

Proof. Putting (17) and (22) into (13), we have

$$
\begin{aligned}
\alpha T_{a}+ & K_{a}+2 \sqrt{(k+\nu) \delta \mu} \\
& +\frac{N_{b} d D(N) / d N}{1-\sqrt{2 N / \delta \psi \xi T_{b}} \cdot(d D(N) / d N)}+w \\
= & \alpha T_{b}+K_{b}+\sqrt{2 \delta \psi \xi T_{b} N_{b}} .
\end{aligned}
$$


In equilibrium, if $N_{a}=0$, that is, $N_{b}=N_{o}^{*}$, Wardrop's first principle leads to

$$
\begin{aligned}
\alpha T_{a} & +K_{a}+2 \sqrt{(k+v) \delta \mu} \\
& +\left.\frac{N d D(N) / d N}{1-\sqrt{2 N / \delta \psi \xi T_{b}} \cdot(d D(N) / d N)}\right|_{N=N_{o}^{*}}+w \\
\geq & \alpha T_{b}+K_{b}+\sqrt{2 \delta \psi \xi T_{b} N_{o}^{*}} .
\end{aligned}
$$

Clearly (37) contradicts (35). Therefore, $N_{a}>0$.

We now prove $N_{G}^{*}>N_{o}^{*}$. If $N_{G}^{*} \leq N_{o}^{*}$, then

$$
D\left(N_{G}^{*}\right)=\alpha T_{b}+K_{b}+\sqrt{2 \delta \psi \xi T_{b} N_{b}} \geq D\left(N_{o}^{*}\right) .
$$

Together with (33), $D\left(N_{G}^{*}\right)=\alpha T_{b}+K_{b}+\sqrt{2 \delta \psi \xi T_{b} N_{b}} \geq$ $\alpha T_{b}+K_{b}+\sqrt{2 \delta \psi \xi T_{b} N_{o}^{*}}$. Thus, $N_{b} \geq N_{o}^{*}$. Since $N_{a}>0$, $N_{a}+N_{b}=N_{G}^{*}>N_{o}^{*}$. This contradicts $N_{G}^{*} \leq N_{o}^{*}$. Therefore, $N_{G}^{*}>N_{o}^{*}$.

With $N_{G}^{*}>N_{o}^{*}, D\left(N_{G}^{*}\right)=\alpha T_{b}+K_{b}+\sqrt{2 \delta \psi \xi T_{b} N_{b}}<$ $D\left(N_{o}^{*}\right)$. Clearly, $N_{o}^{*}>N_{b}$.

Lemma 3 leads to the following proposition.

Proposition 4. Under public ownership, the government will invest the new highway if condition (37) holds.

Proof. With $d^{2} D(n) / d n^{2} \geq 0$ and $N_{G}^{*}>N_{o}^{*}$, we have $\left.(d D(N) / d N)\right|_{N=N_{G}^{*}} \geq\left(D\left(N_{G}^{*}\right)-D\left(N_{o}^{*}\right)\right) /\left(N_{G}^{*}-N_{o}^{*}\right)$.

Thus, together with (20) and (22), we have

$$
\begin{aligned}
\operatorname{SW}( & \left.N_{a}, N_{b}, N_{G}^{*}, s_{G}^{*}, \tau_{G}^{*}\right) \\
= & \int_{0}^{N_{G}^{*}} D(n) d n-N_{G}^{*} D\left(N_{G}^{*}\right) \\
& +\left.N_{a} N_{b} \frac{d D(N)}{d N} \frac{\partial N}{\partial N_{a}}\right|_{N=N_{G}^{*}} \\
> & \int_{0}^{N_{G}^{*}} D(n) d n-N_{G}^{*} D\left(N_{G}^{*}\right) \\
& \quad+\left.N_{b} \frac{D\left(N_{G}^{*}\right)-D\left(N_{o}^{*}\right)}{N_{G}^{*}-N_{o}^{*}} N_{a} \frac{\partial N}{\partial N_{a}}\right|_{N=N_{G}^{*}} \\
= & \int_{0}^{N_{G}^{*}} D(n) d n-N_{G}^{*} D\left(N_{G}^{*}\right) \\
& +N_{b} N_{a} \frac{D\left(N_{G}^{*}\right)-D\left(N_{o}^{*}\right)}{N_{G}^{*}-N_{o}^{*}} \frac{N_{G}^{*}-N_{o}^{*}}{N_{a}-0} \\
= & \int_{0}^{N_{G}^{*}} D(n) d n-N_{G}^{*} D\left(N_{G}^{*}\right) \\
& +N_{b}\left(D\left(N_{G}^{*}\right)-D\left(N_{o}^{*}\right)\right) .
\end{aligned}
$$

With (34) and (39), we have

$$
\begin{aligned}
\operatorname{SW} & \left(N_{a}, N_{b}, N_{G}^{*}, s_{G}^{*}, \tau_{G}^{*}\right)-\operatorname{SW}\left(N_{o}^{*}\right) \\
> & \int_{0}^{N_{G}^{*}} D(n) d n-\int_{0}^{N_{o}^{*}} D(n) d n+N_{o}^{*} D\left(N_{o}^{*}\right) \\
& -N_{G}^{*} \cdot D\left(N_{G}^{*}\right)+N_{b}\left(D\left(N_{G}^{*}\right)-D\left(N_{o}^{*}\right)\right) \\
= & \int_{N_{o}^{*}}^{N_{G}^{*}} D(n) d n+N_{o}^{*} D\left(N_{o}^{*}\right) \\
& -N_{G}^{*} \cdot D\left(N_{G}^{*}\right)+N_{b}\left(D\left(N_{G}^{*}\right)-D\left(N_{o}^{*}\right)\right) .
\end{aligned}
$$

With $d D(n) / d n<0$, mean value theorem leads to

$$
\begin{array}{r}
\int_{N_{o}^{*}}^{N_{G}^{*}} D(n) d n=D(\zeta)\left(N_{G}^{*}-N_{o}^{*}\right)>D\left(N_{G}^{*}\right)\left(N_{G}^{*}-N_{o}^{*}\right), \\
N_{o}^{*}<\zeta<N_{G}^{*} .
\end{array}
$$

Together with (41) and $N_{o}^{*}>N_{b}$, (40) yields

$$
\begin{aligned}
& \operatorname{SW}\left(N_{a}, N_{b}, N_{G}^{*}, s, \tau\right)-\operatorname{SW}\left(N_{o}^{*}\right) \\
&= D(\zeta)\left(N_{G}^{*}-N_{o}^{*}\right)+N_{o}^{*} D\left(N_{o}^{*}\right)-N_{G}^{*} \cdot D\left(N_{G}^{*}\right) \\
&+N_{b}\left(D\left(N_{G}^{*}\right)-D\left(N_{o}^{*}\right)\right) \\
&>\left(D(\zeta)-D\left(N_{G}^{*}\right)\right)\left(N_{G}^{*}-N_{o}^{*}\right)>0 .
\end{aligned}
$$

This result states that, if condition (37) holds, since introducing a new road improves the total social welfare, the government will invest the new toll road.

Under private ownership, we denote $N_{P}^{*}$ as the solution to the MNB problem. Similarly, we have Lemma 5.

Lemma 5. In equilibrium, under private ownership, $N_{P}^{*}>$ $N_{o}^{*}>N_{b}$ if

$$
\alpha T_{a}+K_{a}+2 \sqrt{(k+\nu) \delta \mu}+w<\alpha T_{b}+K_{b}+\sqrt{2 \delta \psi \xi T_{b} N_{o}^{*}} .
$$

Proof. Putting (30) and (31) into (13), we have

$$
\begin{aligned}
\alpha T_{a} & +K_{a}+2 \sqrt{(k+\nu) \delta \mu} \\
& -\frac{N_{a} d D(N) / d N}{1-\sqrt{2 N / \delta \psi \xi T_{b}} \cdot(d D(N) / d N)}+w \\
= & \alpha T_{b}+K_{b}+\sqrt{2 \delta \psi \xi T_{b} N_{b}} .
\end{aligned}
$$

In equilibrium, if $N_{a}=0$, that is, $N_{b}=N_{o}^{*}$, Wardrop's first principle leads to

$$
\alpha T_{a}+K_{a}+2 \sqrt{(k+\nu) \delta \mu}+w \geq \alpha T_{b}+K_{b}+\sqrt{2 \delta \psi \xi T_{b} N_{o}^{*}} .
$$

Clearly (45) contradicts (43). Therefore, $N_{a}>0$.

Similarly, as Lemma 3, we have $N>N_{P}^{*}>N_{b}$.

With Lemma 5, we have the following proposition. 
Proposition 6. Under private ownership, a private agency will invest the new toll road if condition (43) holds.

Proof. With Lemma 5, we have $N_{a}=N_{P}^{*}-N_{b}>N_{P}^{*}-N_{o}^{*}>0$. Equation (32) directly leads to $P R\left(N_{P}^{*}, s_{P}^{*}\right)>0$.

Proposition 6 states that the demand for trips without introducing a new highway and the system parameters satisfy (43), a private firm will certainly invest in the new highway since it can earn a positive profit.

\section{Conclusions}

This paper investigated how and why to introduce a new "addon" road into an existing transit network. Commuters either use their private cars on a bottleneck-constrained highway or choose regularly dispatched trains for travelling from a residential area to a workplace. Taking into account the OMC, the joint optimization of the toll and capacity level for a new toll road added to an existing transit network under four ownership/tolling regimes was investigated. We found that, whenever flat toll and fine toll are imposed, in a competitive highway/transit network with constant returns to scale in road construction, an optimally designed and priced addedon publicly owned highway would lead to a deficit; that is, the toll revenues are insufficient to cover its all costs, whereas an optimally designed and priced added-on privately owned highway would lead to a positive net benefit, and the net benefit is exactly equal to the total markup with respect to all autocommuters. The conditions to introduce a new "add-on" highway to the existing transit network were derived under different ownership regimes.

Although the transportation system studied in this paper is simple and the body congestion in train carriage is linear, the insights obtained are useful for enhancing our understanding of the dynamic and combinatorial commuting behavior and joint optimization of road toll and capacity level. The research framework adopted in this paper can be extended to consider joint optimization of road toll and transit fare, parking pricing [28], heterogeneous commuters [29], stochastic travel time [30], and even more complex transportation systems. These are our ongoing works.

\section{Conflict of Interests}

The authors declare that there is no conflict of interests regarding the publication of this paper.

\section{Acknowledgments}

This research was supported by Grants from the National Natural Science Foundation of China (71071004, 71101098, 71271004, and 71371128).

\section{References}

[1] C. Winston, "Conceptual developments in the economics of transportation: an interpretive survey," Journal of Economic Literature, vol. 23, pp. 57-94, 1985.
[2] A. de Palma, S. Proost, and S. van der Loo, "Network development under a strict self-financing constraint," Networks and Spatial Economics, vol. 12, no. 1, pp. 109-127, 2012.

[3] H. Mohring and M. Harwitz, Highway Benefits: An Analytical Framework, Northwestern University Press, Evanston, Ill, USA, 1962.

[4] E. T. Verhoef and J. Rouwendal, "Pricing, capacity choice, and financing in transportation networks," Journal of Regional Science, vol. 44, no. 3, pp. 405-435, 2004.

[5] R. Arnott and M. Kraus, Self-Financing of Congestible Facilities in a Growing Economy, Department of Economics, Boston College, 1995.

[6] R. Arnott, A. de Palma, and R. Lindsey, "A structural model of peak-period congestion: a traffic bottleneck with elastic demand," American Economic Review, vol. 83, pp. 161-179, 1993.

[7] S. Hakim, P. Seidenstat, and G. W. Bowman, Privatizing Transportation Systems, Praeger, Westport, Conn, USA, 1996.

[8] A. de Palma, "A game-theoretic approach to the analysis of simple congested networks," American Economic Review, vol. 82, no. 2, pp. 494-500, 1992.

[9] P. A. Viton, "Private roads," Journal of Urban Economics, vol. 37, no. 3, pp. 260-289, 1995.

[10] E. Verhoef, P. Nijkamp, and P. Rietveld, "Second-best congestion pricing: the case of an untolled alternative," Journal of Urban Economics, vol. 40, no. 3, pp. 279-302, 1996.

[11] L. Zhang and D. Levinson, "The economics of road network ownership: an agent-based approach," International Journal of Sustainable Transportation, vol. 3, no. 5-6, pp. 339-359, 2009.

[12] A. De Palma and R. Lindsey, "Private toll roads: competition under various ownership regimes," Annals of Regional Science, vol. 34, no. 1, pp. 13-35, 2000.

[13] Z. Tan, "Capacity and toll choice of an add-on toll road under various ownership regimes," Transportation Research E, vol. 48, no. 6, pp. 1080-1092, 2012.

[14] S.-W. Chiou, "Bilevel programming for the continuous transport network design problem," Transportation Research B, vol. 39, no. 4, pp. 361-383, 2005.

[15] L. Dimitriou, T. Tsekeris, and A. Stathopoulos, "Evolutionary combinatorial programming for discrete road network design with reliability requirements," in EvoWorkshops 2007, vol. 4448 of Lecture Notes in Computer Science, pp. 678-687, April 2007.

[16] T. E. Keeler and K. A. Small, "Optimal peak-load pricing, investment and service levels on urban expressways," Journal of Political Economy, vol. 85, pp. 1-25, 1977.

[17] D. O. Stahl, "Economic analysis of transportation pricing, tax and investment policies," Transportation Research Record, vol. 791, pp. 14-20, 1981.

[18] D. M. Levinson and D. Gillen, "The full cost of intercity highway transportation," Transportation Research D, vol. 3, no. 4, pp. 207-223, 1998.

[19] D. C. Newbery, "Road damage externalities and road user charges," Econometrica, vol. 56, pp. 295-316, 1988.

[20] K. A. Small, M. W. Clifford, and A. E. Carol, Road Work, Brookings Institution, Washington, DC, USA, 1989.

[21] B. De Borger, F. Dunkerley, and S. Proost, "Capacity cost structure, welfare and cost recovery: are transport infrastructures with high fixed costs a handicap?" Transportation Research $B$, vol. 43, no. 5, pp. 506-521, 2009.

[22] A. Horowitz and J. Sheth, "Ride sharing to work: an attitudinal analysis," Transportation Research Record, vol. 637, pp. 1-8, 1977. 
[23] Q. Tian, H.-J. Huang, and H. Yang, "Equilibrium properties of the morning peak-period commuting in a many-to-one mass transit system," Transportation Research B, vol. 41, no. 6, pp. 616631, 2007.

[24] H. J. Huang, Q. Tian, H. Yang, and Z. Y. Gao, "Modeling the equilibrium bus riding behavior in morning rush hour," in Proceedings of the 9th Annual Conference of the Hong Kong Society of Transportation Studies, pp. 434-442, Hong Kong, 2004.

[25] W. X. Wu and H. J. Huang, "Equilibrium and modal split in a competitive highway/transit system under different road-use pricing strategies," Journal of Transport Economics and Policy, vol. 48, no. 1, pp. 153-169, 2014.

[26] K. A. Small, "The scheduling of consumer activities: work trips," American Economic Review, vol. 72, no. 3, pp. 467-479, 1982.

[27] G. Roth, Roads in Market Economy, Avebury, Aldershot, Okla, USA, 1996.

[28] L. D’Acierno, M. Gallo, and B. Montella, "Optimisation models for the urban parking pricing problem," Transport Policy, vol. 13, no. 1, pp. 34-48, 2006.

[29] V. A. C. van den Berg and E. T. Verhoef, "Congestion pricing in a road and rail network with heterogeneous values of time and schedule delay," Transportmetrica A, vol. 10, no. 5, pp. 377-400, 2014.

[30] D. Watling, "User equilibrium traffic network assignment with stochastic travel times and late arrival penalty," European Journal of Operational Research, vol. 175, no. 3, pp. 1539-1556, 2006. 


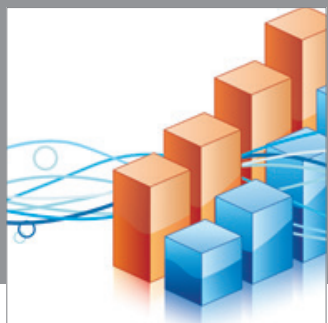

Advances in

Operations Research

mansans

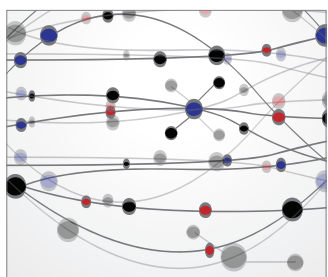

The Scientific World Journal
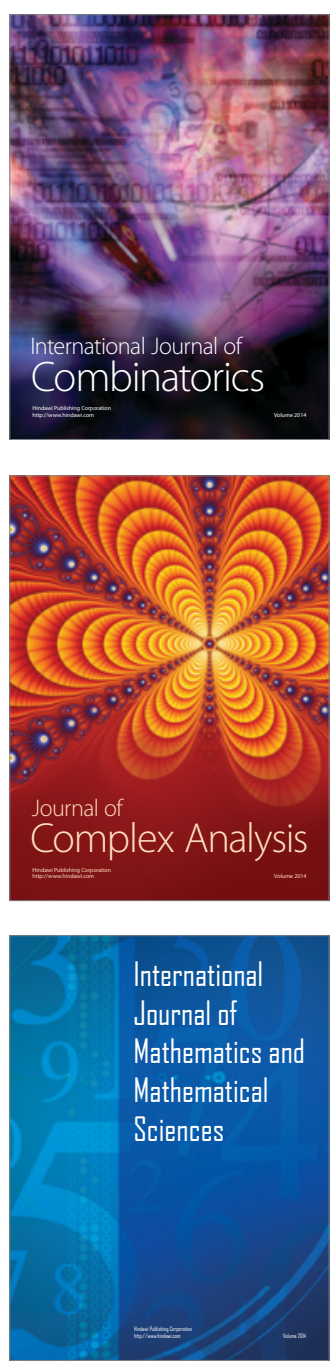
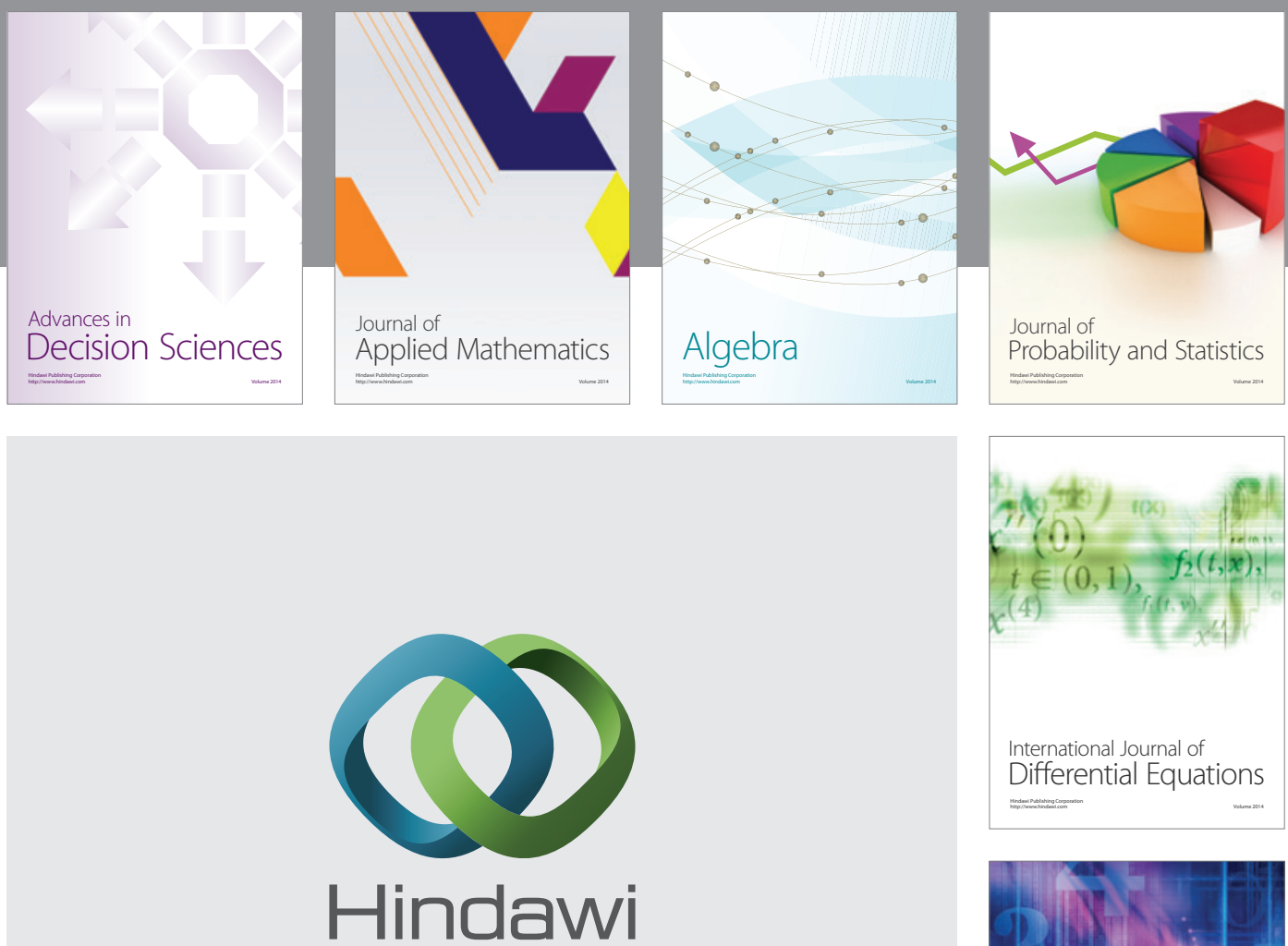

Submit your manuscripts at http://www.hindawi.com
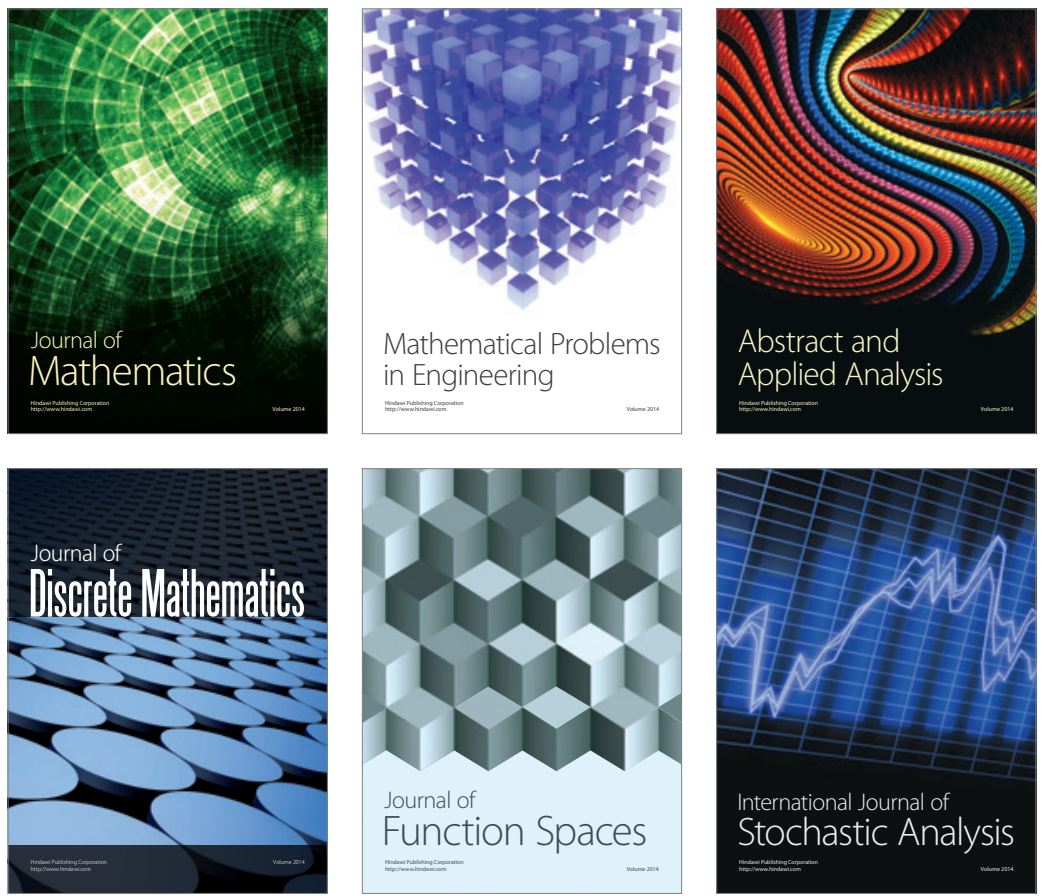

Journal of

Function Spaces

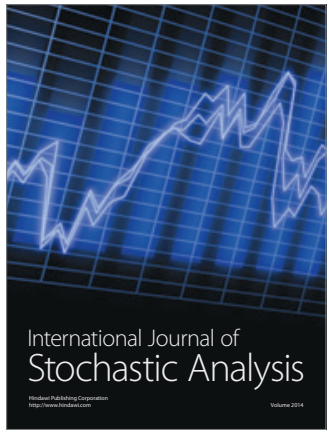

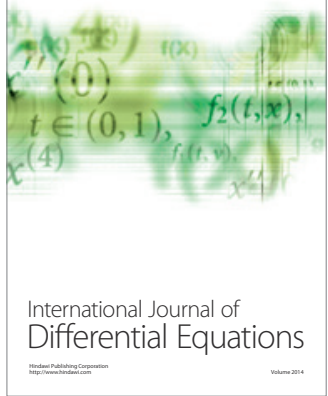
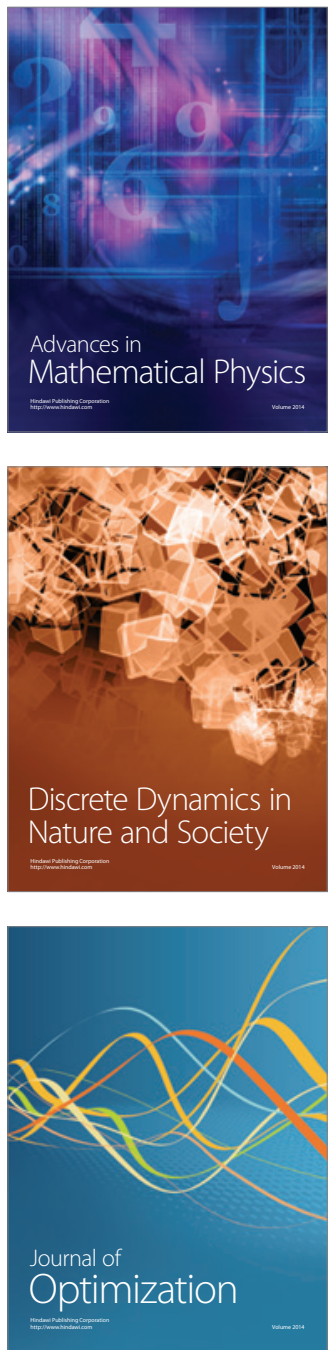